Fecha de recepción: diciembre 2017 Fecha de aceptación: marzo 2018 Versión final: julio 2019

\section{Analysis of Ongoing Transition Projects in Barcelona. An Approach to Transition Design from a Southern Perspective}

Tània Costa Gomez *

\begin{abstract}
This paper analyses a series of ongoing transition projects in the city of Barcelona and the region of Catalonia, using the Transition Design framework. The selected projects focus on rather structural elements of societal transition, such as work schedule, energy, housing, internet infrastructure and culture. The background of the study is a conference held in June 2017 under the title "Southern Perspectives on Transition Design" at EINA, the University of Design and Art of Barcelona (UAB). The study analyses each project using the Transition Case Study Template in order to generate reflections for each sector, coordinate their efforts and ascertain which southern perspectives - if any emerge from local contexts.
\end{abstract}

Key words: Transition Design - bottom up initiatives - southern perspectives - societal transition - Barcelona - systemic creative practices.

[Abstracts in spanish and portuguese at page 197]

(*) Tània Costa Gomez, BA and PhD in Fine Arts from the University of Barcelona (UB). Contemporary art and design theory teacher at EINA, University of Design and Art of Barcelona (UAB). Sub-coordinator of the EHEA Official Master's: Research Master in Art and Design at EINA and Universitat Autònoma de Barcelona. Researcher in art, design and philosophy research projects, including "Generating Knowledge in Artistic research: Towards an Alternative Account. A Meeting Point of Philosophy, Art and Design (MINECO FFI2015-64138-P). Coordinator of the Research Group Design for Transition, Social Innovation and Sustainability at EINA, University of Design and Art of Barcelona (UAB). https://eina.academia.edu/TàniaCosta

This article presents research on the initiatives of several local groups within the area of Barcelona, Cataluña, Spain, groups sharing the aim of Transition Design to create new sustainable lifestyles. As will be seen, these groups also coincide in other aspects, such as methodology, content, criteria and values. These local initiatives are not design studios, even though in some cases designers do participate in their work teams. The aim of the research presented here is precisely to find confluences between Transition Design dynamics and groups of people who work on common challenges from other fields. More specifically, the study aims to enrich both spheres by relating them to each other while 
also drawing the attention of Transition Design scholars to analogous initiatives that stem from citizens and social movements and networks.

In this case, local character clearly is marked by a cultural tradition that we call "southern": in this case, "southern" refers to the South of Europe, which, in many aspects, mirrors South America or Latin America. We consider this parallel to be a relevant factor and, therefore, it has been taken into account when analysing their development.

This research represents an initiative by a research group known as Design for Social Innovation \& Transition Design of EINA-Universitat Autònoma de Barcelona. Funded by Spain's Ministry of Economy, Industry and Competitiveness (MINECO FFI2015$64138-\mathrm{P})$, the project, supervised by full professor Gerard Vilar, is entitled, Generating Knowledge in Artistic Research: Towards an Alternative Account. A Meeting Point of Philosophy, Art and Design.

These research groups have been carrying out fieldwork for the last three years via debates with design undergraduates, meetings with experts, attendance of international congresses and the composition of academic essays (Costa \& Garcia i Mateu, 2015). Content production and data collection culminated in a symposium called "Southern Perspectives on Transition Design", which was held at the University of Design EINA in Barcelona on 8 and 9 June, 2017.

\section{Southern Perspectives on Transition Design: The Symposium}

The symposium intended to provide an optimum research activity where the actors involved -the objects and subjects of analysis- could meet and interact. This interaction then could serve as an agent of change in order to generate new experimentation, collaboration, communication and promotion territories.

\section{Designing the Format}

With these aims in mind, a symposium program was designed with a format specially created to generate the proposed flows of investigation. A group of third year students at EINA's Degree of Design volunteered to collaborate in its creation. The program included the following stages:

1. An inspirational lecture by Terry Irwin: This lecture took place in a cultural space in the centre of Barcelona in the form of an activity open to the general public.

2. Session at the university: This session included presentations about local initiatives as well as a debate between Terry Irwin, Guideon Kossoff and Cameron Tonkinwise from Carnegie Mellon University, Pittsburg, USA. The session concluded with a round table discussion with the participants, mainly of interest to professionals or scholars.

3. Workshop: Guests were invited from local initiatives where Transition Design analysis applied to their organisations was approached. Space was dedicated to activating the ideas and knowledge generated during the previous session debate by guest participants and professors, researchers, students and supporters. 
4. Academic sessions at the university: The session presentations were framed within the following topics: a) Southern perspectives on Transition Design; b) New lifestyles for transition. c) Design, art and (or) contemporary thought in (for) transition. d) Transition projects presentation.

5. Publication: A monographic issue will be published on social innovation, sustainability and Transition Design in the research group's journal, Design Processes. Advanced Practices in Art and Design. The issue, expected to be released in 2018, compiles abstracts of the communications, reviews and related contributions.

6. Context: Efforts were made to hold the debate in a context relevant to participant professionals, in this case the Barcelona Design Week. It was also important to involve a representative academic program, the Doctorate Philosophy Program of Universitat Autònoma de Barcelona.

\section{The Invited Initiatives}

The local initiatives invited were selected with the aim of creating a collaboration network that would function beyond the scope of the symposium, one that could create relationships between the university environment, professional design field and related civic associations and initiatives. The selection criteria began with the selection of groups which work effectively with the idea of changing lifestyles in order to achieve a more sustainable way of life. Attention also was paid to the fact that they were collaborative, non- hierarchical, participative organisations represented by citizens or of a collective nature.

The participating initiatives included the following:

- Som Energia: A non-profit green energy consumer cooperative that produces and commercialises renewable energy in order to "promote a change from the current energy model to a $100 \%$ renewable model...managed by citizenship...To promote the growth of a more sociable and solidary economy... To part from the current energy oligopoly" (Som Energia, 2017).

- Guifi.net: A commons telecommunications network that is open, free and neutral: "Guifi-net is a bottom-up, citizenship-driven technological, social and economic project with the objective of creating a free, open and neutral telecommunications network based on a commons model...Moreover, it generates a model for collaborative economic activity based on proximity and sustainability" (Guifi, 2017).

- Sostre Cívic: A cooperative for the promotion of official handover homes: "home projects with a fairer and more accessible, non-profitable, non-speculative and transforming model and, at the same time, a more solidary way of life in tune with social economy values: equality, equity, democracy and self-management" (Sostre Civic, 2017).

- Idensitat: An artistic project:

In continuous transformation to become a complex system, incorporating other projects, actions or interventions, promoting processes, organising exhibitions, publishing...A system based on collaborative dynamics in order to build a relationship between contemporary artistic practices and social space, 
through research, production, education in a particular context, and distribution throughout a wider context (Idensitat, 2017).

- Reforma Horaria: An independent civic initiative:

Formed by a diverse group of people united by a common objective: to promote a positive transformation in our society through a change of schedules... A change in our use of time can promote more civic habits, strengthening equality among people, our ability to improve relations and, above all, our health and well-being (Reforma Horaria, 2017).

\section{The Academic Sessions}

The academic sessions in the communications presentation were grouped by thematic affinity and were developed simultaneously. They were designed to give importance to the final debate phase of each session, so the moderators were the coordinators of the research groups from the university. An agile formula was established for presentation dynamics, a formula that could be replicated as many times as necessary according to the flow of communications, synchronously in different classrooms; however, the sessions did not extend jointly beyond two hours in duration. Both the abstracts and the articles derived from these sessions are in the process of being published in the Journal of Design Processes (JDP) from the research group of the same name at the design university EINA-UAB.

With a perspective on the transition from eco-design and attention to the sustainable use of materials, presentations adhered to topics, such as exhibition design, fashion, urban furniture, architecture, alternative media to paper and ergonomics. The communications directly related to Transition Design referred to topics including pedagogy, human rights, the Palestinian conflict, synthetic biology and the hospital field. In the last group's debate, several speakers joined together in a critique of what, in their opinion, was a lack of political positioning in Transition Design's general approach.

During the dialogue, speakers noted that politics was surely one of the characteristics of the southern perspective of the Transition Design; therefore, this feature would be one of the next topics of study in the Research Group's activities. It is possible that the southern practice of Transition Design could be less agile and pragmatic than the Anglo-Saxon vision because of the political struggles in Latin societies. At this moment in Catalonia, for example, the political situation conditions all social, economic and cultural activity. This circumstance makes it almost impossible to carry out the exercise of envisioning a future scenario without a political and ideological position.

From the "southern" perspective, all social issues are also political issues. It should be noted that the context of the aforementioned debate is a university born in 1967 during the Spanish Franco dictatorship; it developed a counter-hegemonical cultural discourse that, inevitably, was also political. It also should be noted that EINA studies focus on art and design, both of which inform any emergent debates. In a sense, when the philosopher Boris Groys develops the idea of the anti-aesthetic attitude towards the product of design and art, he illustrates that the current discourse has become more complex in another 
direction: "The problem is not the incapacity of the art of becoming truly political; the problem is that the contemporary political sphere is already aestheticized" (Groys, 2014).

\section{Design Decisions Toward a "Relational Welfare"}

To finish this account of the symposium, we can highlight the fact that while developing the symposium, we attempted to apply the idea of relational welfare (Cottam, 2011) to a research activity in the academy context. Consequently, hierarchies were avoided between guest participants and invited audience members. The physical space, including the furniture, was arranged especially to suit this aim. During the debates held at the university's conference hall, chairs were distributed circularly and the general public and guests were mixed with no specific order. Professors and the director of Carnegie Mellon University's Faculty of Design sat in the audience despite their positions as principal actors in the symposium. This circumstance made corporal movement necessary in order for the speakers to be seen and heard, a situation that generated dynamic spaces where speakers and participants had to move.

In terms of design, we also decided to dismiss the translation service common at this kind of event in Spain, with headphones for each member of the audience. Instead, several people able to translate to and from Catalan-Spanish-English were placed in strategic places among the audience members and next to the guests. Their task was to assist understanding in moments of special difficulty and to provide specific linguistic hints. Instead of being considered external to the session, such interactions, interruptions and discursive exchanges became part of the research development.

Though it appears trivial, the lunch setting was devised to continue the debate's dialogue -research activity via creative debate (Costa \& Huertas, 2016) in a more relaxed forum. A single round table with no seat assignments was placed in the garden. Here, guests and audience members shared delicious rice cooked in the same pan. The inspiration for this setting came from an interview with Catalan artist Antoni Miralda in which he regretted the lack of communication between the artists selected to participate in a Sao Paolo biennial called, "How to Live Together". As Miralda (2006) put it, "What we don't have here is a huge table where all of us can sit at and chat, which is a pity...". For Miralda, rice is an inclusive food that dissolves power hierarchies among diners because it is a basic and elemental food for most of the world's population. This communication between diners, then, can evolve into conversation, into exchange -rewarding and without constraints- of thoughts and experiences really valued by people who talk as part of their identity.

The same philosophy of design was followed when choosing the location for the opening conference with Terry Irwin. Ultimately, the event was held at Cercle Artístic Sant Lluc, the oldest art association in the city. Most of the participating artists and local designers have been members of this association at some point. Another reason for this choice is the location's central position in the city's old quarter, in front of Market Santa Caterina, one of the busiest markets in Barcelona and an international reference point for architectonic design after its reform. Therefore, it is a space of articulation, and of local material, human and symbolic exchange transcending global extension. In terms of the character and features of the place, the conference hall used lacks the typical shape of an auditorium, but it 
is the social space used by members of the artistic circle. The specific configuration of the space and the distribution of furniture promote communication between users and allows for free-flowing conversation. The nature of the space thus permits a format combining conference and conversation.

\section{Case Study: Idensitat. Can Transition Design Encompass Systemic Artistic Projects?}

This section delves into the analysis of the IDENSITAT initiative, presented in the symposium entitled, "Southern Perspectives on Transition Design" via the Transition Design Case Study of the School of Design Carnegie Mellon University [CMU], a system developed by Terry Irwin, Guideon Kossoff and Cameron Tonkinwise.

We have chosen this case study because of its singularity and the opportunities for innovation it provides to Transition Design research. The use of CMU's template on an artistic project like IDENSITAT can help to illustrate the confluences between relationalcontextual artistic practices and projects on design of services, systems and interactions (Costa, 2012). In the present case, we take a step forward with the aim of defining the areas of intersection and/or non-distinction between the Transition Design perspective and another artistic approach.

As will be made clear during the analysis, correspondences between both practices reflect not only methodology but also content. In 2016, Idensitat held a conference known as "IN TRANSITION - CITY. Artistic Practices and Social Spaces" as part of the "Cohabitar entre" project. The conference included debates, lectures, work tables, case studies, an urban tour and a documentary, with the aim of analysing the idea of transition in the city and its actual transformation abilities:

The city, the urban environment, and its most complex, most tense, most dynamic, most (re) appropriated, most collaborative, most creative, most political configuration, that is to say, 'public space', is what is brought together here as a space in transition; understanding the city as artwork, as a place for enjoyment, as an object of value, and, above all, as a collective creation, the result of decisions taken and acted upon by citizens...The transition-city creates a dialogue among scenarios which contributes to the transformation of cities based upon various perspectives and positions, examples of contemporary transition taking place in the modes of production, and examples of the active citizen participation in shaping public space and the contemporary construction of cities.

It is clear that this idea of the transition-city is not exactly the same as that of the transition-town, exemplified by the English city of Totnes and its predecessor Rob Hopkins. Both conceptions, however, can enrich each other when they enter into a dialogue and exchange values, attitudes and activities. Actually, the transition-city promoted by Idensitat is more akin to current Transition Design proposals, especially in regards to its systemic view and collective development. 
Another motivation justifying our interest in this comparative analysis exercise is the investigation of possibilities for the Transition Design format to embrace artistic projects and/or to share fundamental aspects that can evolve into explicit collaboration. This issue is particularly interesting for the University of Design EINA in Barcelona (Universitat Autònoma de Barcelona) because we have fostered a collaboration on an Idensitat artistic project, between its director Ramón Parramon, a Transition Design professor at Carnegie Mellon University Cameron Tonkinwise, and two designers involved in transition processes: Mercè Rua and Adrià Garcia i Mateu. In the study, we have made use of the Transition Design Case Study template explicitly, while making changes to some titles and adjusting some content based on the purpose of this development.

\section{Project Profile: A Systemic Approach}

Idensitat is an art project that works in tandem with other art, design, architecture and anthropology projects with the aim of developing intervention initiatives in the social space. Idensitat promotes connections between groups of people, disciplines and institutions in order to investigate, experiment and influence the territory from a local basis. Idensitat's general approach considers creative processes to be agents of change for the social space while sharing approaches, methodologies and aims with participative design. Indeed, many of its participants are designers.

On a spatial basis, the starting point is always what is local (the neighbourhood), but it aims to generate and connect several territorial nodes, forming a network that can be projected into a more global context. A description of the ID Barrio Eix Besós project carried out in 2016-2017 by Idensitat provides this explanation: "It is grounded in dynamics based on artistic practices, activating processes for the collective benefit and which can have an impact on the neighbourhoods where the project is implemented, and project them later into a more global dimension" (Idensitat, 2017).

In terms of time, Idensitat produces projects to be implemented in the mid-term: from one to four years. The longest projects (c. nine years) result from adding together small projects generated from a specific location and spreading them out in bordering, nearby or, in some cases, far away spaces. Temporalities, therefore, vary according to the stagedevelopment of each project. For its part, continuity beyond intervention depends on the action having been absorbed by the actual context; in addition, users must keep developing it autonomously, with users understood not only as local inhabitants but also as institutions and agents with the ability to transform the place.

The first stages of the design project probably are developed more thoroughly than its final stages of production and application. The following aspects are developed fully: identification of the problem, analysis of the "ecosystem", implications for the citizen groups, relationships between participant agents, ideation workshops, implementation of process development activities, collection-sampling-collectivisation of proposals and prototype start-up. The less fully developed aspects include product implementation, testing, redesigning and impact evaluation. These work stages, planned in relation to objectives, are described in project de ID Barrio Eix Besós: 
This is achieved by analysing the space in order to understand its dynamics, visualising in order to interpret the various operating conjunctions, sketching out projects in order to encourage new productive dynamics, and collaborating locally in order to enhance and multiply creative capacities.

The format of Idensitat has the potential to become a Transition Design solution, especially via a connection/integration approach. This potential results from the fact that its projects are devised as a meeting point of other projects and because relationships between entities, groups, agents and institutions are encouraged. Projects expand to multiple levels because they do not remain focused on only one area of study and/or action. Instead, they link different points of view, staging similar but not identical interests while encouraging a diversity of methodologies and collaborations between disciplines. In this case, the artistic project serves as a mediator, coordinator, facilitator and activator of intervention practices in real spaces, with the cooperation of residents.

In this sense, a clear coincidence is observed with the agglutinating function, coordinating and facilitating of the Transition Designer. In both cases, the act of projecting, typical of the traditional role of the designer, takes place in the action of "infrastructuring", a concept that Bjögvinsson, Ehn and Hillgren use in their definition of the new role of the designer. This conception is born of rethinking the participatory designer's role and pushing it further, towards the role of articulation-connection-integration:

This infrastructure is shaped over extended timeframes, not only by professional designers, but also by users as mediators and designers...Infrastructuring entangles and intertwines activities at project time (e.g., selection, design, development, deployment, and enactment) with everyday professional activities at use time (e.g., mediation, interpretation, and articulation), as well as with further design in use (e.g., adaptation, appropriation, tailoring, re-design, and maintenance) (Bjögvinsson et al., 2012).

In every Idensitat project and in its subprojects, various organizations of a differing nature participate: the European Community Cultural Program, state and/or municipal departments of culture, district council civic centres, local associations of different kinds, educational and university environments, inter-university research groups, citizen groups, collectives of designers and artists and art institutions.

The global Idensitat project includes the following participants: Generalitat de Catalunya, Department of Culture; Barcelona City Council, Institut de Cultura; Ajuntament de Manresa; Fundación/Colección Júmex; HANGAR (Bacelona); Fabra i Coats Fàbrica de Creació de Barcelona; Xarxa Transversal; Ajuntament de Mataró; Vilanova i la Geltrú City Council; Creative Europe Programme of the European Union; and Xarxa d'Espais de Producció Xarxaprod.

The organizational chart changes its construction depending on the type of project, linking different agents, associations and institutions in each case. This process is consistent with the systemic vision of Transition Design, which also visualizes problems as part of 
a network of relationships. Some of the artistic and design collectives involved in these networks include Makea, Todo por la praxis, La Fundició and Urban Recipes.

\section{Transversal Aesthetics for a Change of Perception as a Previous Step Towards a Transition to New Sustainable Lifestyles}

Idensitat clearly works with an eye on mid- and long-term sustainable futures, especially at the intersection between the social, territorial-local and urban environments. More than generating views of future sustainable lifestyles, it activates changes in the perception of current scenarios in order to facilitate the outcome of such futures. Contrasting with design forecast that anticipates a lifestyle model to be achieved, this kind of systemic artistic project paves the way for change without establishing its future form while highlighting the need to transition towards new sustainable lifestyles.

Projects are approached collectively and on a participatory basis, in collaboration with the population affected by a social, urban, demographic or identity problem. These projects seek to improve the group's quality of life via interdisciplinary creative processes as well as the creation of connections between the communities, local agents, institutions and entities involved. The issues to be dealt with stem from the confluence of different obstacles, located in multiple scales; they cannot be confronted by focusing on a single cause. Projects therefore are composed of different coordinated activities and of microinterventions that try to embrace situational complexity.

A cosmopolitan localism (Manzini, 2006) is established, developing itself with varying intensities in different projects. Even though it is not achieved universally in the global project, it is one of the platform's aims. For example, the ID Barrio project has been developing since 2009 in specific locations in Barcelona, Mexico and Sao Paolo. The projects occur on the bordering areas between the districts of large cities and participants seek to incorporate them in a positive way into the lives of local residents. Projects and micro projects have been created specific to each city, but they share methodologies and objectives. This exchange demonstrates that the methodologies work in different contexts so long as they can be adapted to the particular identity of each new location in collaboration with the local agents involved. The methodologies of approximation for the issues worked upon in ID Barrio have been used as a starting point for work proposals of the following platforms: ID Barrio Besós (2016-2017), ID Barrio Barcelona (2009-2017), ID Barrio Mex (2013) and ID Barrio Sao Paulo (2010).

For its part, ID Estéticas Transversales has produced several similar versions of a project in the Spanish cities of Manresa, Mataró, Vilanova i la Geltrú, Avinyó, Huarte, Burlada and Villava. The projects connect artistic practices, educational activities and social spaces in medium-sized cities. The typology of these cities led to fieldwork on the kind of articulations existing between urban and rural spaces, and, consequently, into an analysis of how these bordering spaces affect the social body that inhabit them. The proposals born from the cooperative activities coordinated by Idensitat focus their attention on the need for perceptual changes regarding relationships and the visibility of the social space and its inhabitants. This change in perception regarding one's own context is necessary in order to make lifestyle changes. 
ID Estéticas Transversales understands artistic practice as an activating force of different fields of action flowing transversally through them:

Bringing together projects which, taking the arts as a medium for experimentation and action, impact upon unique elements of each of the participant cities, and which bring these elements together based upon common themes and shared strategies. The programme deploys transverse processes between artists, educators and active agents in social space, places where the connections between urban space, rural space and the natural environment shape unique realities.

Certainly, we find a clear parallel between the role of the Transition Designer and his or her role as a facilitator and coordinator of organizations. As Guy Julier noted:

The role of the Designer becomes a 'facilitator', which does not necessarily mean that designers have less power or that their work is limited to organize and materialize the wishes of a group of individuals, but must take advantage of their experience to...challenge the collective imagination and to create new dispositions. In doing so they reconnect the public, practices and location (Julier, 2010).

\section{Theory of Change: Creative Processes as Agents of Change in the Social Space}

We would structure project Idensitat's theory of change following Iñigo Retolaza Eguren's methodology, based on the following points: the desired change, the starting points, the interventions and routes of change, and indicators.

1. The desired change:

- The social space is empowered to self-manage its welfare.

- Creative processes are used by citizens and institutions as agents of social change.

- The change is transformational, that is, flexible and fluid, acting on temporary readjustments in order to maintain "realities which are politically, socially and economically fairer and more equitable" (Eguren, 2007).

2. Starting points, actors of change and institutional balance:

- Social space residents express their wish to change their context and the perception they have of it (cognitive institutions).

- The interdisciplinary agents act as collaborators that develop creative processes (cultural institutions).

- The project is linked to local entities involved in the issues which are dealt with (associative institutions).

- The project has the support of some of the formal institutions affected (constitutive institutions).

3. Interventions and route of change:

- It is important to constitute a platform as an urban observatory of each project. 
- All actors involved should be gathered to facilitate dialogue among parties.

- Gathering agreements and activities between collaborators is necessary.

- The project is linked to educational programs and/or university research.

- There is a set meeting point for participants during the development of the project. There is a common place to show or display the work that has been carried out.

- Visibility is granted to the issues treated and the intervention process through communication actions.

- Project methodologies are adjusted to other environments, transforming that which is local into a global network.

4. Indicators: Indicators include the following:

- Detecting the use of creative processes by groups of citizens;

- Adopting methodologies of creative processes by institutions;

- Increasing research in art and design regarding this paradigm.

\section{Art and Design Processes to Visualize Social Relationships: An Activist Strategy to Transition}

Idensitat was born in 1999 as a public and independent call for artistic and interdisciplinary participation in the Catalan location of Calaf. Public space intervention projects were called for, particularly those related to the local context and engaged in the social environment. Over the years, Idensitat has widened its scope of action and modulated its tenets, but it has maintained its alternative and independent spirit with respect to the artistic, educational, cultural and social institutions with which it collaborates. Idensitat depends on several regional and municipal subsidies, but they are granted by different organisms, and the project is not attached to any institution in particular; therefore, it does not have to justify its results or position before a single thought entity.

Projects developed by Idensitat clearly diverge from the socio-economic paradigms of the prevailing neoliberalism. They instead opt for creating solutions to social space problems in collaboration with citizens, with horizontal hierarchy dynamics, generating cooperative organisational structures while involving and engaging local institutions. Collaborating entities are not private entities that promote themselves commercially. The projects are collaborative and open, and therefore act with a holistic view and attitude that does not yield to unidirectional worldviews or single-minded perspectives and ideologies.

This collaborative, open and holistic perspective gets to the heart of both art and design. In Idensitat projects, art is understood as an "artistic" practice of intervention on reality with the aim of promoting changes in points of view and lifestyles in the environments worked upon. For this reason, its bonds with the place are fundamental, as expressed in one of its inaugural texts: “...experimenting with the place to transform artistic practices and experimenting with artistic practices to transform the place".

Every Idensitat project develops artistic and design practices in collaboration with people and organisations that work in local contexts. For example, project proyecto ID Barrio Eix Besós works on the issue of isolation-connection between three neighbourhoods in Bar- 
celona bordering river Besós - Bon Pastor, Trinitat Vella and Baró de Viver. The peripheral location of the three neighbourhoods and the economic difficulties of a segment of their populations are factors that have influenced the territorial segregation and lack of attention on the part of institutions for many years. In the last decade, the situation has been reversed with municipal investment in infrastructure, cession of facilities, urban regeneration and the recovery of the river for use, enjoyment and recreation.

This recuperation process has been made possible by the intervention of neighbourhood and popular movements traditionally linked to collective vindication struggles for the improvement of the common (Marina Garcés, 2013). The task of Idensitat is to join this existing context and to create a platform that acts as an urban observatory for experts, artists, designers and local agents to collaborate in the research and production of proposals and solutions to the lack of connection between the three neighbourhoods.

Design is approached as "investigation through" design in a live laboratory, empathically engaged with the environment on a co-creation basis. In fact, artistic practices also can be interpreted as research. Both in the design and the artistic development, the focus is on the process of collaborative development more than on the solution of the problem posed and final product. In this sense, contextual artistic practices and the design of services and/or systems share dematerialized and systemic views of the creative process.

One of the objectives of ID Barrio Eix Besós is to grant visibility to the existing social relations in the three neighbourhoods, relationships that have been hidden for a long time due to territorial isolation and the lack of public spaces to meet and interchange. Nicolas Borriaud called this situation "relational riffraff" (Borriaud, 1998) an invisibilization strategy carried out by certain nations in order to destroy relational capacity in public spaces. This strategy intended to sweep away from public spaces those structures that could foster alternative discourses and/or generate dissident thinking.

\section{Conclusion: Systemic Creative Practices as a Methodology in Transition in the Face of Wicked Problems}

As discussed above, the Contemporary Design course of the Master's Degree in Art and Design Research at EINA-UAB is taught by Idensitat's Director, Ramon Parramon, and by Transition Designers Mercè Rua and Adrià Garcia i Mateu, with the occasional collaboration of Cameron Tonkinwise, CMU scholar and expert in Transition Design. The results from sharing these three points of view on transition -together with the interaction between an actual project and the educational field- will be one of the lines of study followed by the Research Group.

The introductory text of the course establishes the initial connection and fieldwork from which to interact: "systemic creative practices and spaces in transition". The articulation of what is systemic involves detecting and managing complexities that are related to other levels of reality. From this position, it becomes inevitable to understand artistic practice and design practice as non-autonomous disciplines, with the ability to connect and be connected to multiple agents. Analysing this practice from an extra disciplinary approach places us in a favourable position to face the development of processes, their multiple so- 


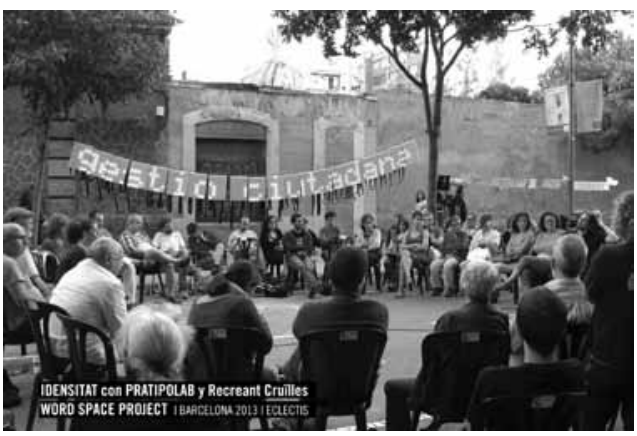

Figure 1.

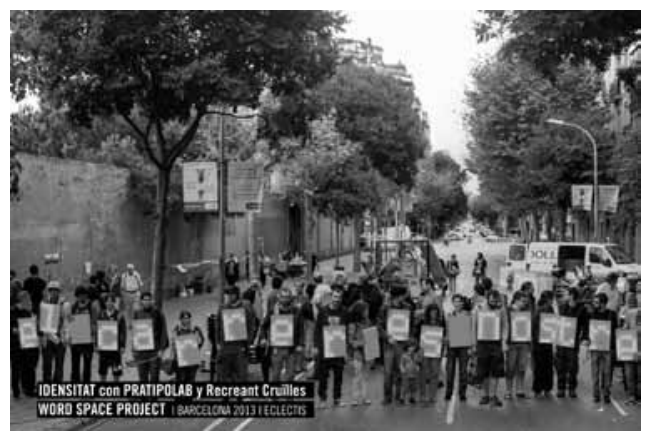

Figure 2.

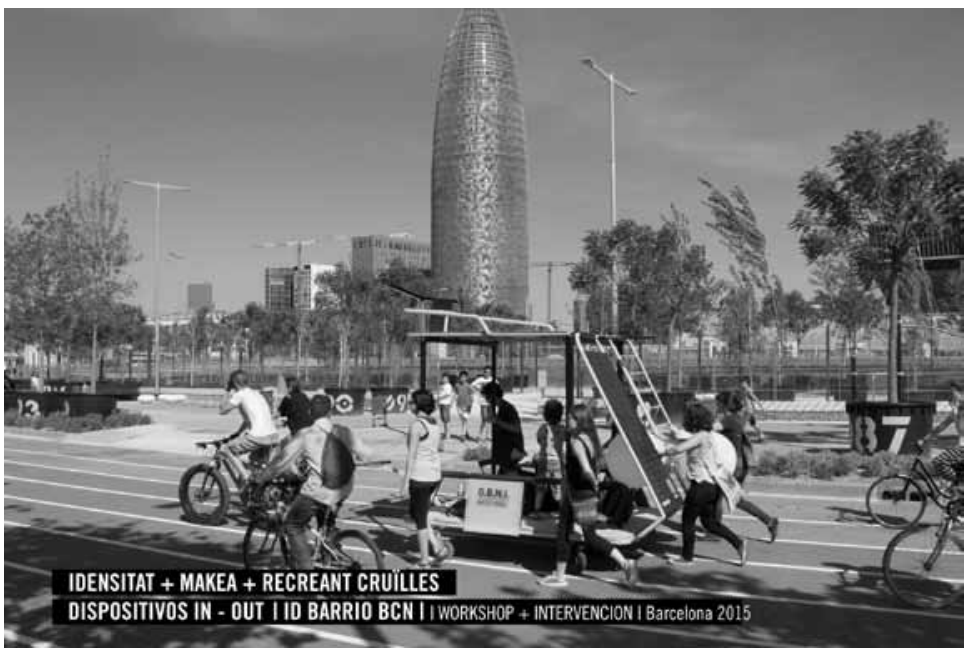

Figure 1. Word Space Project. Gestió ciutadana. Idensitat 2013. Figure 2. Word Space. El carrer és nostre. Idensitat 2013. Figure 3. Dispositivos In-Out. Idensitat, Barrio Barcelona 2015.

Figure 3.

lutions and the decision-making based on a management of complexities. This approach prioritizes the creation of systems over the creation of objects, guiding them to spaces undergoing transitory processes (Parramon, 2017).

Systemic creative practices, including art and design (Parramon, 2017), have a flexible and changing structural constitution adequate for addressing projects that fall within the definition of wicked problems. The wicked problems, to which Transition Design draws its attention, have that condition of indeterminacy which Richard Buchanan distinguished from the undetermined and which, according to the author, was best approached from an interdisciplinary action where art and design could collaborate (Buchanan, 1992). The Idensitat projects that we have cited throughout the article have impacted public and social 
spaces with a transitory nature, places where various wicked problems converge: environmental degradation, educational deficits, urban ills and social inequity. In public spaces in transition, there is no possibility of isolating a single wicked problem upon which to focus actions. The 10 points for identifying wicked problems proposed by Rittel in 1972 retain validity in the exercise of detecting them in public spaces in transition, where they emerge in plural. Doing a reverse analysis exercise, that is, trying to identify those 10 points from the work process of systemic creative practices is also a way of clarifying them and making them emerge towards the visibility needed to solve them.

To conclude this article, we have used the concept of "systemic creative practices" as a proposal to encompass different types of constellations-of-actions developed in design and art projects in favour of transition. We also have recovered Rittel's original definition of wicked problems and Buchanan's classic one, because the link between the creative processes of art and design is better explained using these perspectives over others.

We would also like to highlight that this article serves as an account of a research process following a symposium format designed as a "tangible event" through which to generate the research itself: the writing of objectives, the choice of case studies, the design experiences within the symposium, the academic communications session, the publication of a volume in the university journal with the resulting content and, finally, the writing of this essay all developed as a research exercise "on" and "through" design and art.

\section{References}

Bjögvinsson, E. Per-Anders. (2012). Design things and design thinking: contemporary participatory design challenges. Design Issues, 28(3).

Borriaud, N. (1998). Esthétique relationnelle. Dijon: Les presses du Réelle

Buchanan, R. (1992). Wicked problems in design thinking. Design Issues, 8(2), 8-21.

Costa, T. (2012). Arty diseny. Processos sense objecte. Situaciones. Revista de historia y crítica de las artes de Barcelona, n 5, p. 22-28. Barcelona: Escola d'Història de l'Art de Barcelona.

Costa, T., \& Garcia i Mateu, A. (2015). Transition Design. Metodologías de diseño colaborativo para procesos de emancipación ciudadanos. Revista de Estudios Globales y Arte Contemporáneo, Volumen 3, Núm. 1, 66-84. Barcelona: Researcher Group Art Globalization Interculturality, Universidad de Barcelona.

Costa, T., \& Huertas, S. (2016). Creative debate as a tool to empower and create disruptive thinking within learning contexts in a university design environment. Procedia - Social and Behavioral Sciences, 228, 413-417.

Garcés, M. (2013). Un mundo común. Barcelona: Edicions Bellaterra.

Groys, B. (2014). Volverse público. Buenos Aires: Caja Negra Editora.

Irwin,T., Kosoff, G., \& Tonkinwise, C. (2016). Transition Design case study. Pittsburgh: School of Design Carnegie Mellon University.

Julier, G. (2010). La cultura del diseño. Barcelona: Gustavo Gili.

Manzini, E. (2006). Creative communities, collaborative networks and distributed economies. Promising signals for a sustainable development. Milano: Politecnico di Milano. 
Miralda, A. (2006). Entrevista a Lara Almarcegui y Antoni Miralda. Dos españoles en la Bienal de Sao Paulo. El cultural. Madrid: Prensa Europea del Siglo XXI, S.A. http://www. elcultural.com/revista/arte/Lara-AlmarceguiAntoni-Miralda/18832.

Retolaza, E. I. (2010). Teoria del cambio. Un enfoque de pensamiento-acción para navegar en la complejidad de los procesos de cambio social. Guatemala: PNUD/Hivos.

Rittel, H., \& Webber, M. (1973). Dilemmas in a general theory of planning. Policy Sciences, 4, 155-169.

Resumen: Este trabajo analiza una serie de proyectos de transición en curso en la ciudad de Barcelona y la región de Cataluña, utilizando el marco de Diseño para la Transición. Los proyectos seleccionados se centran en elementos bastante estructurales de la transición social, como el horario de trabajo, la energía, la vivienda, la infraestructura de Internet y la cultura. El fondo del estudio es una conferencia realizada en junio de 2017 bajo el título "Perspectivas del Sur en Diseño para la Transición” en EINA, la Universidad de Diseño y Arte de Barcelona (UAB). El estudio analiza cada proyecto utilizando la Plantilla de Estudio de Caso de Transición con el fin de generar reflexiones para cada sector, coordinar sus esfuerzos y determinar qué perspectivas del sur, si las hay, surgen de contextos locales.

Palabras clave: Diseño para la transición - iniciativas ascendentes - perspectivas del sur transición social - Barcelona - prácticas creativas sistémicas.

Resumo: Este trabalho analisa uma série de projetos de transição que se desenvolvem na cidade de Barcelona e na região de Catalunha, utilizando o marco do Design para a Transição. Os projetos eleitos se centram em elementos estruturais da transição social, tal como o horário de trabalho, a energia, a habitação, a infraestrutura de Internet e a cultura. A base do estudo é uma palestra realizada em junho de 2017 denominada "Perspectivas do Sul em Design para a Transição" em EINA, a Universidade de Design e Arte de Barcelona (UAB). O estudo analisa cada projeto utilizando o modelo de Estudo de Caso de Transição com o propósito de gerar reflexões para cada setor, coordenar seus esforços e determinar que perspectivas do sul surgem de contextos locais.

Palavras chave: Design para a Transição - iniciativas ascendentes - perspectivas do sul transição social - Barcelona - práticas criativas sistémicas. 